\title{
DEVELOPING READING COMPREHENSION ABILITIES
}

\author{
ABDULLAH FARIH \\ Islamic University of Lamongan, Indonesia \\ farichabdullah@gmail.com
}

\begin{abstract}
:
Teaching reading a second or foreign language receives a special focus. Some students of foreign language give the most important goal. They get the information through reading, as like newspaper, books, article, etc. good reading text also provide good writing models. So it needs strategies in order to get the best value in the process and the final output. Some strategies are proposed by the expert, but we should select where the appropriate to teach on the students. The aim of the study is to know what the best way to teach reading comprehension students as a second or foreign language is. It is important because nowadays, there are many book sources that use English as their language. This article will discuss (1) the strategies for reading comprehension, (2) the understanding of reading comprehension and teaching reading comprehension. The finding of the study show that the way of teaching reading comprehension is different; and it must adopt the strategy of reading comprehension of the students.
\end{abstract}

Keywords: reading strategy, reading comprehension.

Different people use the term reading in different ways, and much confusion can arise from consequent misunderstanding. So we had better start by making sure that we are thinking about the same thing (Nuttal, 1989: 1).

Research on reading in a second or foreign language has been much developed recently. One of the purposes is, of course, as an effort to improve second or foreign language reading instruction. The importance of having reading strategy for a learner has also been suggested by many experts, as the following:

Strategy use during reading is a major research topic for educational psychologists and reading instruction specialists, but it is less commonly addressed by cognitive psychologists and discourse comprehension researchers (cf. Lau \& Chan, 2003; Magliano, Trabasso, \& Graesser, 1999; McNamara, 2004;
McNamara et al., 2007; oakhil \& yuill, 1996; Perfetti, Landi, \& Oakhill, 2005; Rapp et al., 2007 cited in Grabe, 2009: 51).

L2 research on working memory is relatively minimal. Working memory measures correlate with reading abilities for L2 students (Harrington and sawyer, 1992; Walter, 2004; Geva and Ryan, 1993, cited in Grabe: 2009: 35). Reading is the core of the syllabus because by reading a book most students learn. Only by reading can students acquire more knowledge when they want to learn new content in their discipline and when they leave schools.

From the reason above, English teachers should consider to make various efforts on teaching in order to make the student independent in learning. Based on the theories discussed in this article, the writer suggests that actually teachers cannot only develop students' reading 
skills but also other language skills as like writing skills during teaching reading comprehension.

This article will discuss (1) the strategies for reading comprehension, (2) the understanding of reading comprehension and teaching reading comprehension

\section{The Strategies for Reading Comprehension}

Most of the students of second or foreign language reading comprehension are primarily matter to develop reading strategy. According to Brown (2001: 306), some strategies related to bottom-up procedure, on other enhance to top-down processes. There are ten strategies that proposed:

\section{Identify the purpose of reading}

Before reading something we should make decision. Why do we read? What do we want get from it? We will find a variety of reasons for reading. According to Nuttal (1989: 19) said that in FL learning reading is often used for purposes which are different from those found in mother-tongue learning. Furthermore, reading ability can be improved by teaching how to read for particular purposes. (Anderson, 2000, cited in Grabe: 2009: 7)

2. Use graphemic rules and patterns to aid in bottom-up decoding (especially for beginning level learners).

3. Use efficient silent reading techniques for relatively rapid comprehension (for intermediate to advanced levels).

4. Skim the text for main ideas.

5. Scan the text for specific information.

6. Use semantic mapping or clustering.

7. Guess when you aren't certain.

The students or learners can use guessing to their advantage to:
Guess the meaning of a word

Guess a grammatical relationship

$>$ Guess a discourse relationship

Infer implied meaning

- Guess about a cultural reference

$>$ Guess content messages

8. Analyze vocabulary.

Some techniques are useful here:

Look for prefixes

$>$ Look for suffixes

$>$ Look for roots that are familiar

Look for grammatical contexts that may signal information.

Look at the semantic context (topic) for clues

9. Distinguish between literal and implied meanings

This requires the application of topdown processing skills. The fact not all the language can be interpreted by attending literal meaning or surface structure, but they need implied meaning. Implied meaning refers to pragmatic information.

10. Capitalize on discourse markers to process relationships.

Many discourse markers in English signal relationships among ideas as expressed through phrases, clauses, and sentences. A clear comprehension of such markers can greatly enhance learners' reading efficiency.

According to Peter Westwood (2008: $45)$, there are three strategies of reading comprehension:

\section{POSSE}

This strategy was used successfully with grade 4,5 and 6 students and deals with processing expository text. It is designed to activate students' prior knowledge about a topic and to link it with new information contained in the text 
(Englert \& Mariage, 1991 cited in Westwood: 45). A 'strategy sheet' is used to cover the fi ve aspects listed below, and students add information to it in the form of a semantic map before, during and after the reading. The sheet provides a visual guide that provides direction and structure, linking what students already know with new information that is acquired while reading.

The five letters in the acronym POSSE stand for:

$\checkmark$ Predict what issues will be covered in the text (based on your existing knowledge of the subject) and raise a question you want to answer.

$\checkmark$ Organise your predicted points and question and link them into a semantic map.

$\checkmark$ Search the text (read carefully to confi rm or discredit your predictions).

$\checkmark$ Summarise the points gleaned from the reading.

$\checkmark$ Evaluate your understanding of the text and what you have learned from it.

POSSE relies heavily on teacher modelling and thinking aloud, and even more on instructional dialogue between teacher and students and within the group of students.

\section{Directed Reading-Thinking Activity (DRTA)}

DRTA has some features in common with POSSE. It is a wholeclass instructional strategy designed to give students experience in previewing text before reading, predicting what an author may say, reading the narrative text to confi rm or revise the predictions and elaborating upon responses
(Snowball, 2005 cited in Westwood, 2008:45). Questioning by the teacher encourages the students to think analytically and critically about the subject matter they are reading. In order for some students with reading diffi culties to get the most benefi $t$ from DRTA, it is usually necessary to have them re-read the passage, aiming for improved fl uency so that cognitive effort can be redirected towards the meaning of the paragraphs.

The DRTA process involves three basic steps:

$\checkmark$ predicting some of the information you may fi nd, or raising some questions you hope to have answered in the text

$\checkmark$ reading the text carefully, with your predictions and questions in mind

$\checkmark$ being able to prove, with evidence from the text, any conclusions you make from your reading.

The teacher's involvement is mainly to ask focusing questions to activate students' prior knowledge and to stimulate thinking. For example: 'What do you think will happen? What is this likely to be about? How would she be feeling? Why do you think that? Can you prove what you say from something in the book?'

\section{The 3H strategy (Here - Hidden - or in my Head)}

The purpose of this strategy for upper primary grades is to teach students where answers to specifi c questions may be found (Graham \& Wong, 1993). The answer is either explicitly stated in the text (here), or is implied in the text and can be inferred if the reader thinks carefully about some information on the page (hidden), or the 
information is not on the page but is already in the student's prior knowledge (in the head) and needs to be recalled. In teaching the $3 \mathrm{H}$ strategy, students are cued to use appropriate text-based or knowledge-based information to answer questions. They are also taught to use self-questioning to help focus their own attention on selecting appropriate information and to monitor their own understanding.

The teacher provides necessary prompting (e.g. the use of cue cards) in the beginning, but this support is faded out as students gain confidence and control of the strategy. The $3 \mathrm{H}$ strategy helps students appreciate that answers to questions are not necessarily stated explicitly within a text, and that often one must think carefully and go beyond the words.

The teaching sequence of the $3 \mathrm{H}$ strategy is as follows:

$\checkmark$ Teacher poses a question related to the text.

$\checkmark$ Teacher demonstrates (by 'thinking aloud') how to locate relevant information on the page (here).

$\checkmark$ Students practise this step to fi nd answers to additional questions, with feedback from the teacher.

$\checkmark$ Teacher demonstrates the second possibility, using information on the page to infer or predict a possible answer (hidden).

$\checkmark$ Students practise step 1 and step 2 together with guidance and feedback.

$\checkmark$ Teacher demonstrates the third possibility, namely that the answer is not here or hidden but must be located from sources outside the text, for example from what a student already knows.
Students practise step 1, step 2 and step 3 with guidance and feedback.

$\checkmark$ Over the following lessons the strategy is reviewed and used again on a variety of text types.

\section{K-W-L strategy (Know - Want to know - Learned)}

This strategy activates students' prior knowledge on a given topic, then invites them to generate some questions they hope the text may answer, and fi nally they must summarise any new information they have learned from the reading (Ogle, 1986, cited in Westwood, 2008: 47). To facilitate this process, a 'KWL Chart' is provide for each student. The chart is ruled up with three columns, headed respectively 'what we know', 'what we want to know', and 'what we learned'. A fourth column might be added to the chart in which students can record their response to the material in the text; or they might write down suggestions for what they will do to make use of the information they have learned to extend their study of the same topic.

The KWL strategy is intended for use with expository texts, and the teacher needs to select material that lends itself well to this type of analysis. Expository text is more diffi cult than narrative text for students to understand, so the subject textbooks used in upper primary and secondary schools often cause problems. So too does the concise informative data presented online when students are conducting computer searches for their projects and assignments. Teachers and tutors need to appreciate the diffi culties students experience with expository text. Most weaker readers need 
guidance to become more aware of the typical structure, style and sequence used within this type of text (Gersten et al., 2001; Williams, 2005, cited in Westwood, 2008: 47). The teaching sequence of the KWL strategy is as follows:

$\checkmark$ Immediately before a non-fi ction text is to be read, the students and teacher brainstorm and list all they know about the topic under the fi rst column.

$\checkmark$ Under the second column they generate some questions or issues that may be answered in the text.

After reading the text, either silently or as a shared activity, the students write a dot-point summary in the third column listing the main things they have learned from the text.

Effective reading comprehension strategies (Grabe, 2009: 209):

\section{Summarizing}

\section{Forming questions}

3. Answering questions and elaborative integrative interrogation

\section{Activating prior knowledge}

5. Monitoring comprehension

Strategies used for comprehension monitoring

1. Has a reading and is aware of it

2. Recognizes text structure

3. Identifies important and main-idea information

4. Relates text to background knowledge

5. Recognizes relevance of text to reading goal(s)

6. Recognizes and attends to difficulties

7. Reads carefully

8. Clarifies misunderstanding

\section{Using text-structure awareness}

1. Levels of importance of information in texts

2. Heading and subheadings

3. Paragraphing choices

4. Co-referential connections across ideas in a text

5. Relations of part-to-part and part-towhole information

6. Transition forms and signal words

7. Pattern for organizing text information (cause and effect, problem and solution, comparison and contrast, description, classification, analysis, argument and evidence, procedural sequence, chronological ordering)

\section{Using graphic organizers}

\section{Inferencing}

Research on multiple-strategy instruction (Grabe, 2009: 231)

Many approaches involving multiple strategies tend to focus on four to eight major strategies, though other approaches may incorporate up to 20 or 30 distinct strategies over a longer period of time. The following discussion emphasizes the research evidence for 11 empirically supported multiple-strategy approaches.

\section{Know-Want to know-Learned (KWL)}

KWL represents a three-stage instructional process for understanding texts: what students know, what they want to know, and what they have learned.

\section{Experience-Text-Relate (ETR)}

Developed as part of the curriculum for the Kamehameha Early Education Program (KEEP) in Hawai, with this approach the teacher activates the students' background knowledge, promotes predictions about the text, and helps students monitor their 
comprehension of the text, form questions about the text, evaluate the text, and reflect on the relation between text information and personal experience through discussion (Saunders \& Goldenberg, 1999).

\section{$>$ Question-Answer-Response (QAR)}

Teachers train students to answer questions on: directly available information, information to be inferred, and information drawing on background knowledge

> Directed Reading and Thinking Activeness (DRTA)

Students relate background knowledge to the text, determine goals for reading, and then engage in predicting activities atset stopping points throughout the text.

\section{$>$ Reciprocal teaching}

This approach to strategy instruction has received consistently strong support from a wide range of research studies. The biggest limitation of reciprocal teaching is that it is designed only for use with reading groups rather than a whole class.

\section{Collaborative Strategic reading (CSR)}

CSR is a promising approach to combined-strategies instruction that draws on both reciprocal teaching and cooperative learning, and that has been used with both L1 and L2 students.

\section{Self-explanation Reading Training (SERT)}

SERT is a recent effort by cognitive psychologies interested in discourse processing to examine the contributions of strategy training to reading comprehension. The method used in SERT instruction asks students to explain their understanding of a text and what makes it possible for them to understand the text well.

\section{$>$ Direct explanation}

It represents an early and ongoing approach to strategies instruction that teaches students how to use strategies in order to comprehend a text better, though no specific subset of strategies is high-lighted over others.

\section{$>$ Questioning the Author}

It is an approach to multiple strategy instruction in which the teacher and students form questions about the text and respond to them.

\section{> Transactional Strategies Instruction (TSI)}

It represents another major approach to combined-strategy instruction. Students are taught a repertoire of strategies over time that is modeled by the teacher and then practiced by students while they work to comprehend instructional texts.

\section{Concept-oriented reading instruction (CORI)}

It is a comprehension approach to reading that promotes multiple strategy use along with content instruction from texts.

\section{Reading Comprehension}

Goodman and Smith suggested that reading was a selective process and was not basically a process of picking up information from the page in word -byword manner. Good readers used their background knowledge and related it with the author intended meaning, predicted information, sampled the text, made the necessary inferences, and confirm the prediction (Grabe, 1994; Long, 1987; Brown, 1994 cited in Hadi: 2008). This theory has influenced ESL reading theory and instructions from the late 1970s to the present. The 1980s was a decade in which many ESL reading theories and practices 
developed Goodman and Smith's perspectives on reading.

As has been synthesized by Grabe (2009: 14) from various sources (Cf. Urquhart \& Weir, 1998; Koda, 2005), a description of reading has to consider the notions that fluent reading is rapid, purposeful, interactive, comprehending, flexible, and gradually developing. It means that:

1. Fluent reading is rapid; the flow of information at a sufficient rate needs to be maintained to make connections and inferences essential for comprehension.

2. Reading is purposeful; the reader has a purpose in reading. In the academic world, for example, the purpose is for obtaining information.

3. Reading is interactive. It means that many skills work together simultaneously in the process. The reader makes use of the information from his/her background knowledge and information intended by the author.

4. Reading is comprehending; the reader usually expects to understand what he/she is reading.

5. Reading is flexible; the reader uses a set of strategies to read efficiently.

6. Reading develops gradually; the reader does not become fluent suddenly, or immediately following a reading development course. Fluent reading is the product of a long-term effort and gradual improvement.

In a slightly different statement, Roe, et al.,1996 cited in Hadi: 2008, clarifies that the essential reading skills and abilities needed in reading content materials are summarized as follows: understanding special concepts and vocabulary; identifying main ideas and supporting details; locating facts or specific details; organizing reading material by determining sequence, drawing conclusions, and finding cause-and-effect relationship; locating information and using reference materials; reading and interpreting graphic aids; adjusting rate to purpose, difficulty and type of content; comprehending at the literal, inferential, critical, and creative levels; developing the habit of extensive reading; and activating background knowledge and experience.

The fluent reading which is a complex process is explained by analyzing the process into a set of component skills: at least there are six general component skills and knowledge areas such as automatic recognition skills, vocabulary and structure knowledge, formal discourse structure knowledge, content background knowledge, synthesis and evaluation skill/strategies, and metacognitive knowledge and skills monitoring. (Grabe, 2009).

Reading, like writing and all other forms of thinking, can never be separated from the purposes, prior knowledge, and feelings of the person engaged in the activity or from the nature of the text being read. The conventions of texts permit the expectations of readers and the intentions of writers to intersect. Global and focal expectations and intentions form a personal specification that readers and writers develop and modify as they proceed through a text. The fluency of reading depends as much on characteristics of the text and reader as on reading ability. Experienced readers who find a text difficult may read like beginners. (Frank, 2004: 193).

So, in the reading comprehension we should consider comprehension and thinking, reading speed, comprehension and context, and benefits of reading. 


\section{The Teaching of Reading Comprehension}

The teaching of reading comprehension should be based on the theory. In fact, the development of teaching reading comprehension has been discussed in various literatures in which experts introduced different concepts about the reading comprehension instruction. Chastain (1989), cited in Hadi, 2008, introduces that the ultimate objective of teaching reading comprehension is to enable the students to comprehend written text which is considered appropriate to their level. According to Alexander (1989) cited in Hadi, 2008, for example, teaching reading should be focused on three levels of comprehension skills, namely, literal, inferential, and evaluation comprehension levels.

The process of strategy identification and feedback entails the naming of strategies and repeated explanation on the teacher's or students' parts as to how to use the strategies. The explanation process can be facilitated by use graphic organizers. The question can be used to lead the students are what, when, and why. (Richard \& Renandya, 2002: 291). The question 'what' can be used to make connecting, evaluating, asking question, checking for answers to questions, and translating. The word 'when' can be used before raeding, while reading, and after reading. And the word 'why' can be used to clarify ideas, to help paraphrase, to evaluate content, to judge the author's idea, to make own opinion, to develop knowledge, to evaluate, to check, to have more interest, to pay attention to what I'am reading, and to get exact meaning.

Literal comprehension as the lowest level requires the recall or recognition of information and ideas explicitly stated in the text being read. Inferential comprehension requires the use of interpretation and prediction, and the reader's personal knowledge in making inferences such as main ideas. Evaluation comprehension requires the reader to make judgment and be critical on the content of the text. Application level requires the reader to be able to apply the concepts or ideas into the real life situation. At last, appreciation level has to do with the reader's emotional reaction to various elements of content.

Although many writers explain reading skills in different ways, the ideas are similar. Principally, the reading skills required are understanding main ideas and supporting ideas intended by the author, relating prior knowledge with those ideas, evaluating, and making inferences and flexible adjustment of strategies used to comprehend the reading text (Willis, 1985; Bright \& McGregor, 1986; Matthews, et al., 1986; Long \& Richards, 1987; Garbutt \& Kerry, 1996 Cited in Hadi, 2008).

Those understandings imply that the objective of teaching reading comprehension should be helping learners to develop all of the reading comprehension skills. The teaching techniques and strategies should be directed to achieve those objectives.

\section{Conclusion and Suggestions}

From the discussion it can be concluded that the integrated language skills including reading and writing, can be developed through the teaching of reading comprehension. This integrated skills instruction must be planned in such a way that all language skills are displayed in the classroom tasks and activities. Although the development of reading skills involves 
qualitatively different processes from the development of oral language ability, both are underpinned by certain principles.

Reading comprehension involves various processes that can be taught to the students through various strategies. It is those strategies which stimulate the students' language skills performed. With careful reflection and planning, any teacher can integrate the language skills and strengthen the tapestry of language teaching and learning. When the tapestry is woven well, learners can use English effectively.

The writer suggests that any teacher who intends to apply teaching reading comprehension should:

$>$ Be able to select the materials which the students have been familiar with so they have owned prior knowledge about the topic;

Be able to make leading questions to the students;

Be able to apply the strategies that appropriate to the students;

Possess not only language knowledge but also content knowledge; and

Have teaching competences.

\section{REFERENCES}

Brown, H. D. 2001. Teaching by Principles: an interactive approach to language pedagogy (2 $2^{\text {nd }} E d$.). New York: Pearson Education Company.

Grabe, William. 2009. Reading in a Second Language: Moving from Theory to Practice. New York: Cambridge University Press

Hadi, L. S. 2008. Developing Integrated Skills through the Teaching of Reading Comprehension in Content Area. TEFLIN Journal.
Nuttall, C. 1989. Teaching Reading Skills in Foreign Language. Oxford: Heinemann International.

Richards, J.C. \& Renandya, W.A. 2002. Methodology in Language Teaching: An Anthology of Current Practice. Cambridge: Cambridge University Press.

Smith, Frank. 2004. Understanding Reading. London: Lawrence Erlbaum Associates Publishers. Westwood, Peter. 2008. What Teachers need to know about: Reading and Writing Difficulties. Australia: ACER press 